\title{
Prevalence of cigarette smoking among employees of the Mexican National Institutes of Health
}

Raúl H. Sansores, M. en C., ${ }^{(1)}$ Jaime Villalba-C aloca, M.C., (1) Loredmy Herrera-K iengelher, Lic. en Soc., ${ }^{(1)}$ Alejandra Soriano-Rodríguez, Lic. en Psic., ${ }^{(2)}$ Alejandra Ramírez-Venegas, M. en C.(1)

\section{Sansores RH, Villalba-Caloca J, Herrera-Kiengelher L, Soriano-Rodríguez A, Ramírez-Venegas A. Prevalence of cigarette smoking among employees of the Mexican National Institutes of Health. Salud Publica Mex 1999;41:381-388.}

\begin{abstract}
A bstract
Objective.To determine the prevalence of cigarette smoking at the $\mathrm{N}$ ational Institutes of Health in Mexico (N IHM). Material and methods. A survey was performed among workers who voluntarily answered a questionnaire. Smokers were identified with two specific questions, and type of employment was classified as physicians, administrative staff, investigators and support personnel. Results. Total prevalence smoking was 28\% (of 4422 answered questionnaires). It was significantly higher among females, among administrative staff, and common-law and separated workers. It was significantly higher at the Mexican Institute of Psychiatry than at the remaining Institutes, even after adjusting for confounding. The prevalence was also higher among physicians from the same Institute. 0 the smokers, $46 \%$ do so in their work areas and $78 \%$ of them would like to quit. Conclusions The prevalence of smokers at the N IHM is as high as in the general population and a broad educational program for tobacco control and prevention is needed.
\end{abstract}

Key words: smoking; $\mathrm{N}$ ational Institutes of $\mathrm{H}$ ealth; physicians; Mexico

\author{
Sansores RH, Villalba-Caloca J, Herrera-Kiengelher L, \\ Soriano-Rodríguez A, Ramírez-Venegas A. \\ Prevalencia de tabaquismo \\ en los trabajadores de los institutos \\ nacionales de salud en México. \\ Salud Publica Mex 1999;41:381-388.
}

\section{Resumen}

Objetivo. Determinar la prevalencia de tabaquismo en los trabajadores de institutos nacionales de salud en México (Insalud). Material y métodos Se realizó una encuesta entre trabajadores que voluntariamente contestaron un cuestionario; se identificó al fumador con dos preguntas específicas y se indagó la actividad laboral clasificada en médicos, administradores, investigado res y servicios generales. Resultados. La prevalencia de fumadores fue de $28 \%$ (4 422 cuestionarios respondidos). Fue significativamente mayor en trabajadores del sexo femenino, administradores, trabajadores que viven en unión libre y separados. El Instituto Mexicano de Psiquiatría (IMP) mostró la prevalencia más elevada, aun después de un ajuste por confusores.También fue mayor entre los médicos del Instituto Mexicano de Psiquiatría. De los fumadores, $46 \%$ fuma en sus áreas de trabajo, y $78 \%$ de los fumadores quiere dejar de fumar.Conclusiones La prevalencia de tabaquismo en los Insalud es tan alta como la de la población general y se requiere un programa educativo amplio para el control y prevención del hábito de tabaco.

Palabras clave: tabaquismo; institutos nacionales de salud; médicos; México

(1) Departamento de Investigación en Tabaquismo. Instituto $\mathrm{N}$ acional de Enfermedades Respiratorias, México.

(2) División de Investigaciones Epidemiológicas y Sociales. Instituto Mexicano de Psiquiatría, México.

Recived on: 0 ctober 22, 1998 - Accepted on:A pril 7,1999

Reprint requests to: RH Sansores. Departamento de Investigación en Tabaquismo, Instituto N acional de Enfermedades Respiratorias. Calzada de Tlalpan 4502, 14080 México, D. F., México.

E-mail: rsansore@ mail.cpesa.com.mx 
C igarette smoking remains the major preventable worldwide cause of morbidity and mortality. ${ }^{1,2}$ In Mexico, the prevalence of smoking among the general population is $25 \%{ }^{3}$ and an estimate of 118 daily deaths can be attributed to tobacco use. ${ }^{4}$ Although health care providers should be the model and the main advisers for cessation and prevention, this may not be the case in Mexico. Recent reports ${ }^{5}$ suggest that the prevalence of smokers among a sample of Mexican physicians is as high as among the general population. In order to gather information on cigarette smoking among workers at the National Institutes of Health in Mexico (NIHM), a survey of smoking habits was conducted among physicians, nurses, administrative and support staff workers. The NIHM is one of Mexico's leading research, education, and clinical centers. Therefore, the findings obtained from this survey were obtained from subjects well qualified in promoting tobacco control and prevention.

\section{Material and methods}

Population. Workers from nine of the ten National Institutes of Health and one General Hospital in Mexico were invited to answer a questionnaire on tobacco use. Data from the National Institute of Public Health were unintentionally omitted and do not appear in this report. Each Institution has a worker's profile in terms of the medical specialty and intensity of the research activity. The following Institutes were included: respiratory diseases (Instituto Nacional de Enfermedades Respiratorias), cardiology (Instituto Nacional de Cardiología Ignacio Chávez), oncology (Instituto Nacional de Cancerología), psychiatry (Instituto Mexicano de Psiquiatría), neurology (Instituto Nacional de Neurología y Neurocirugía Manuel Velasco Suárez), two children's hospitals (Instituto Nacional de Pediatría y el Hospital Infantil de México Federico Gómez, perinatology (Instituto Nacional de Perinatología), one Institute which is a hospital for internal medicine only (Instituto Nacional de la Nutrición Salvador Zubirán), and one general hospital, which is not part of the National Institutes, Hospital General Dr. Manuel Gea González).

Data Collection. A self-administered questionnaire was developed which included age, gender, marital status (single, married, widowed, divorced, separated or common-law relationship), education ( $\leq 6$ year, 7-9 year, 10-12 year, $>12$ year), type and location of employment, work shift (7 AM to 3 PM, 3 PM to 11 PM, 11 PM to7 AM), and smoking status. Employment type was divided into four different groups: a) physicians, b) administrative staff (secretaries, department heads, computer programmers, accountants, auditors, etc.), c) researchers, and d) support staff workers (nurses, $\mathrm{X}$-ray technicians, laboratory technicians, maintenance workers, etc.).

We used two methods to categorize subjects as smokers. The first method considered smokers as those individuals who answered "yes" to the two questions "Do you smoke cigarettes now?" and "Have you ever smoked at least 100 cigarettes in your entire life?" In the second method, the categories used were those from the following self-classification: a) I am a smoker who wants to quit, b) I am a smoker who does not want to quit, c) I am a smoker who has quit some time in the past, d) I am a former smoker, and e) I am a non-smoker. Subjects were also asked if they smoked at work. A pilot study with 64 workers from one Institute was conducted to test the questionnaire. The application time of the questionnaire was estimated to be $15 \mathrm{~min}$ utes and the concordance of the answers after two applications was $96 \%$. No comprehension difficulties were detected among the respondents.

Methods. From October to November 1997, all staff employed by the NIHM was asked to participate in the study. Interest was generated by placing advertisements, signed by the Director of each Institute, in the corridors. With assurance of anonymity, questionnaires were personally distributed during checking-in time of each employee of the NIHM. A brief and satisfactory explanation of the aims of the study was provided by trainee interviewers and subjects were asked to return the questionnaires at checking-out time. One telephone number was available to address questions and clear doubts. At the checking-out time one of the interviewers picked up the questionnaires.

Short version of the questionnaire. Because the results of this survey showed that the response rate was very low (see Results) a short version of the questionnaire containing only the items related to smoking prevalence was once applied in the Institute of Respiratory Diseases in October 1998.

Statistical analysis. Age was analyzed as a continuous variable while all other variables were analyzed qualitatively. Association of smoking status with demographic characteristics, employment type and location were evaluated using a $\chi^{2}$ test. When necessary, Fisher's exact test was used. A stepwise logistic regression model containing terms for gender, age, marital status, education, employment type and location, and work shift was applied in order to determine variables associated with smoking status. The statistic Kappa was used to evaluate concordance between the two 
applications of the questionnaire to check for the reproducibility and the two approaches that we used to identify smokers.

\section{Results}

Table I shows the response rate and prevalence of smokers by Institution obtained from 4422 completed questionnaires. In this analysis the Institutes having the higher prevalence of smokers but contrasting results in the number of responders were eliminated (the higher and the lower respondents rate were for the Institutes of Psychiatry and Oncology, respectively). The results showed no differences in prevalence of smoking among the remaining Institutes while the respondent rate persisted to be significantly different among them. These data suggest that the prevalence of smoking was not biased by the respondent rate. The Institutes with the lowest respondent rate (Oncology and Neurology) were not included. The global prevalence of smokers $(28 \%)$ did not significantly change (OR=1.01, 95\% CI=0.93-1.12). Furthermore, these results suggest that the highest prevalence of smokers at the Institute of Psychiatry was not biased by the Institutes with the lowest respondent rate. Average response rate was 31\% (range, 8 to $75 \%$ ) while the mean prevalence of smokers was $28 \%$ (range, 24.5 to $42.5 \%$ ). Concordance of the two different approaches for identification of smokers was of $95 \%$. The answer to the question do you smoke now? was used to consider a subject as smoker. Table II illustrates the smoking prevalence based on gender, employment type, marital status and education. Data of non-smokers were compared with smokers. In addition, associations between smokers and non-smokers with the general characteristics of subjects were made and described in Table II. The prevalence of smokers was higher in female than in male workers (39 vs. 22\% respectively, $\mathrm{OR}=2.12,95 \% \mathrm{CI}=1.85-2.44)$. The prevalence was also higher among administrative staff than among physicians, researchers and support staff workers (33 vs 22, 25, and 24\%, respectively; $\left.\chi^{2}=49.9, p<0.001\right)$. The prevalence by marital status was higher in widowed, separated workers and in those in common-law relationship, than in married, and single workers $\left(\chi^{2}=38.3, p<0.001\right)$. No statistically significant differences were found in the prevalence of smokers by level of education. The mean age of smokers was not statistically different from that of non-smokers.

Smoking prevalence was higher in the Institute of Psychiatry than in the remaining Institutes even after controlling for gender, age, marital status, education,
Table I

\section{Prevalence of smoking among health workers. Response rate by Institute. National Institutes of Health, Mexico City, 1997}

\begin{tabular}{|c|c|c|c|c|}
\hline Institute & $\begin{array}{l}\text { Prevalence } \\
\text { of } \\
\text { smokers*§ }\end{array}$ & $\begin{array}{l}\text { Number of } \\
\text { questionnaire } \\
\text { answered }\end{array}$ & $\begin{array}{c}\text { Total } \\
\text { number of } \\
\text { workers }{ }^{\ddagger}\end{array}$ & $\begin{array}{c}\text { Response } \\
\text { rate } \\
(\%)\end{array}$ \\
\hline
\end{tabular}

\begin{tabular}{llrrr} 
Psychiatry & 39 & 327 & 434 & 75 \\
\hline O ncology & 42.5 & 87 & 1038 & 8 \\
\hline Cardiology & 24.5 & 664 & 1732 & 38 \\
\hline Respiratory Diseases & 25.4 & 433 & 1592 & 27 \\
\hline Pediatrics & 28.3 & 296 & 2389 & 12 \\
\hline Perinatology & 26.7 & 704 & 1402 & 50 \\
\hline N eurology & 34.2 & 111 & 1075 & 10 \\
\hline IN N SZ & 29.7 & 633 & 2200 & 29 \\
\hline Children's Hospital & 25.1 & 745 & 2300 & 32 \\
\hline GH MG G & 32.7 & 422 & 1510 & 28 \\
\hline Total & 28 & 4422 & 14220 & 31
\end{tabular}

$* \chi^{2}=4.52 p=0.71$

$\neq \chi^{2}=37.5, p<0.001$

$\chi^{2}=36.6, p<0.001$

working timetable and work activity. These data were analyzed using a stepwise logistic regression analysis (table III). Odds ratio values come from different stepwise logistic regression models where each Institute was compared (indicator variable) with the remaining Institutes, including IMP. Table shows only risks yielded for IMP where we observed a consistently significant risk of smoking whenever it is compared with the other Institutes. There was noassociation between smoking and working atother Institutes different to IMP. The Institute of Oncology dropped out by default (by the equation) in all different models because of the size of the sample, this is why it is not compared with the other Institutes despite of an apparently higher prevalence of smokers than the IMP.

Figure 1 shows the prevalence of smoking according to employment type in all Institutes. No differences in smoking prevalence based on employment type were observed within any given Institute. Thus, in those Institutes where the smoking prevalence was high, it was similarly high among physicians, administrators, researchers and support staff workers. Only by examining prevalence by employment type between Institutes, a significantly higher value was found among physicians from the Institute of Psychiatry (see figure 1A). Researchers from the Institute of Cardiology showed a lower prevalence of smoking than the other institutes (figure 1C). 
Table II

Prevalence of smokers by gender, employment TYPE, MARITAL STATUS AND YEARS OF EDUCATION. National Institutes of Health. Mexico City, 1997

Smokers ( $n=1225) \quad$ Non-Smokers $(n=3197)$

\begin{tabular}{lrr} 
Age (years) $($ mean $\pm S D)$ & $39 \pm 12$ & $41 \pm 13^{*}$ \\
\hline Male (\%) & 22.4 & $77.6^{\ddagger}$ \\
\hline Female (\%) & 39.4 & 60.6
\end{tabular}

\begin{tabular}{lll} 
Employment type (\%) & & $\S$ \\
\hline Physicians & 22 & 78 \\
\hline Administrative staff & $33^{*}$ & 67 \\
\hline Researchers & 25 & 75 \\
\hline Support Staff Workers & 24 & 76
\end{tabular}

\begin{tabular}{lll} 
Marital Status (\%) & & $\&$ \\
\hline Single & 28.7 & 71.3 \\
\hline Married & 27.0 & 73.0 \\
\hline Divorced & $36.3^{*}$ & 63.7 \\
\hline Separated & $38.6^{*}$ & 61.4 \\
\hline W idowed & 21.6 & 78.4 \\
\hline Common-law relationship & $38.3^{*}$ & 61.7
\end{tabular}

\begin{tabular}{|c|c|c|}
\hline Years of Education (\%) & & \# \\
\hline$\leq 6$ years & 25 & 75 \\
\hline $7-9$ years & 35 & 65 \\
\hline $10-12$ years & 15 & 85 \\
\hline Technical Career & 27 & 73 \\
\hline University & 29 & 71 \\
\hline Post Doctoral Studies & 28 & 72 \\
\hline 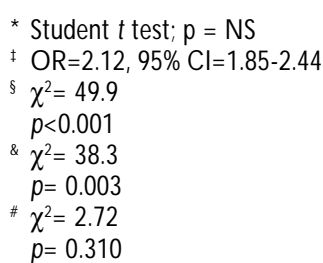 & & \\
\hline
\end{tabular}

Forty-six percent of the staff reported smoking in their work areas and a similar number of researchers $(53 \%)$ and administrative staff $(53 \%)$ do so. However, a significantly greater number of administrative staff smokes in their work areas compared to physicians $[(43 \%), \mathrm{OR}=0.64,95 \% \mathrm{CI}=0.46-0.89]$ and support staff $[(36 \%) \mathrm{OR}=1.99,95 \% \mathrm{CI}=1.5-2.64]$. Table IV shows the smokers' self-described attitude towards the possibility of quitting. In average, $32 \%$ of the smokers want to quit, $23 \%$ do not want to quit and $45 \%$ have quit some time in the past but are still smokers. The desire to quit
Table III

\section{Potential RISK OF SMOKING IF WORKING AT AN INSTITUTE OF Psychiatry IN COMPARISON WITH other Institutes of Health. Mexico City, 1997}

Institute

Odds Ratio (95\% Confidence Limits)

\begin{tabular}{ll} 
Cardiology & $1.79(1.35-2.38)$ \\
\hline Respiratory-D iseases & $1.76(1.28-2.42)$ \\
\hline Pediatrics & $1.48(1.05-2.10)$ \\
\hline Perinatology & $1.65(1.24-2.20)$ \\
\hline N eurology & $1.24(0.77-1.99)$ \\
\hline IN N SZ & $1.69(1.27-2.27)$ \\
\hline Children's Hospital & $1.75(1.31-2.33)$ \\
\hline GHMGG & $1.38(1.01-1.88)$
\end{tabular}

was significantly greater among administrative and support staff workers than among physicians and researchers. Age and gender were not significantly different between subjects who do not want to quit smoking and the remaining smokers. However, smokers who do not want to quit showed a greater education $\left(\chi^{2}=46.16, p<0.001\right)$ than smokers who want to quit or have quit some time in the past. Likewise, in relation to marital status only single in comparison to married subjects showed a significant association with respect to not wanting to quit smoking $(\mathrm{OR}=1.6,95 \%$ $\mathrm{CI}=1.17-2.20)$.

Short version of the questionnaire. In order to look at the effect of the low response rate on the real prevalence of smoking in the Institutes a new survey was made in the Institute of Respiratory Diseases by using a short version of the same questionnaire. The response rate was $84 \%$. Smoking prevalence was $30 \%$ where as in this it work was $25.4 \%$ (see table 1 ). In other words the smoking prevalence that we are reporting in this work understimates, probably because of the lower response rate, the observed prevalence from a more comprehensive survey. However, the difference was not statistically significant $(\mathrm{OR}=0.79,95 \% \mathrm{CI}=0.61-1.03)$.

\section{Discussion}

In average, $28 \%$ of the employees that were surveyed at the NIHM are smokers. Smokers were identified by two different methods (items) and this approach was used to confirm the global prevalence of smoking in the studied sample. Whether or not these data indeed represent the real prevalence of smoking in the NIHM is questionable. However, the similarity in prevalence 
A

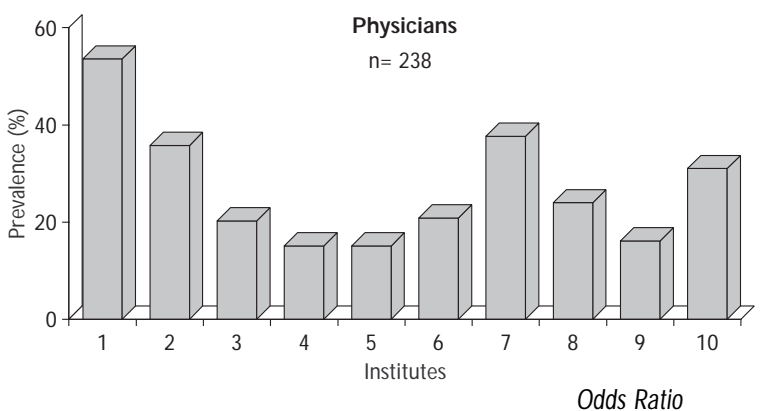

(95\% Confidence Limits)

\begin{abstract}
$4.22(1.39-13.16)$
$4.70(2.12-10.45)$

$6.67(2.77-16.21)$

$6.80(2.09-23.07)$

$4.43(2.83-09.69)$

$1.89(0.56-06.46)$

$3.65(1.55-08.65)$

$6.03(2.79-13.12)$

$2.62(1.18-05.82)$
\end{abstract}

C

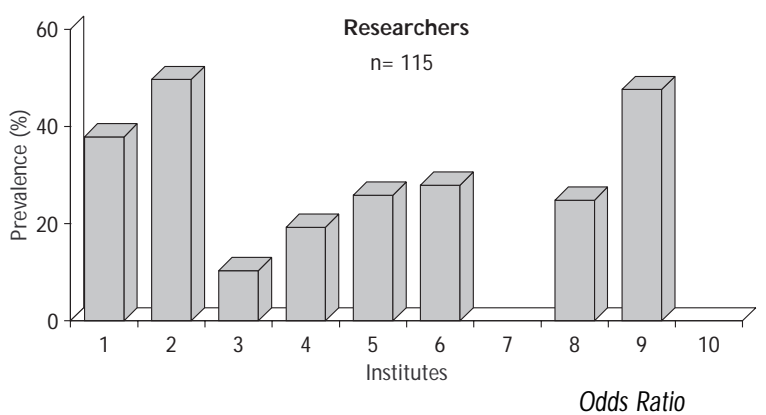

(95\% Confidence Limits)
$0.62(0.14-02.70)$

$5.53(2.13-15.04)$

$2.62(0.74-10.14)$

$1.71(0.66-04.52)$

$1.57(0.74-03.35)$

$1.92(0.99-03.73)$

$1.85(0.79-04.36)$

3.47 (1.89-06.39)

$0.62(0.06-06.62)$

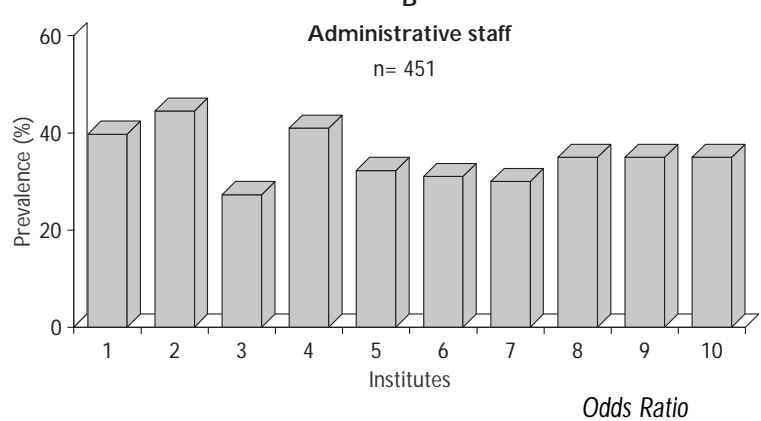

(95\% Confidence Limits)

$\begin{array}{lll}\text { Psychiatry } & \text { vs } & \text { Oncology } \\ \text { Psychiatry } & \text { vs } & \text { Cardiology } \\ \text { Psychiatry } & \text { vs } & \text { Respiratory Diseases } \\ \text { Psychiatry } & \text { vS } & \text { N eurology } \\ \text { Psychiatry } & \text { VS } & \text { IN N SZ } \\ \text { Psychiatry } & \text { vs } & \text { Pediatrics } \\ \text { Psychiatry } & \text { VS } & \text { Perinatology } \\ \text { Psychiatry } & \text { vS } & \text { Children's Hospital } \\ \text { Psychiatry } & \text { vs } & \text { GHMGG }\end{array}$

$0.37(0.17-1.02)$

$1.78(0.63-3.06)$

$0.97(0.54-1.75)$

$1.44(0.85-2.42)$

$1.48(0.92-2.39)$

$1.54(0.63-3.80)$

$1.56(0.97-2.52)$

$1.23(0.74-2.04)$

$1.25(0.76-2.05)$

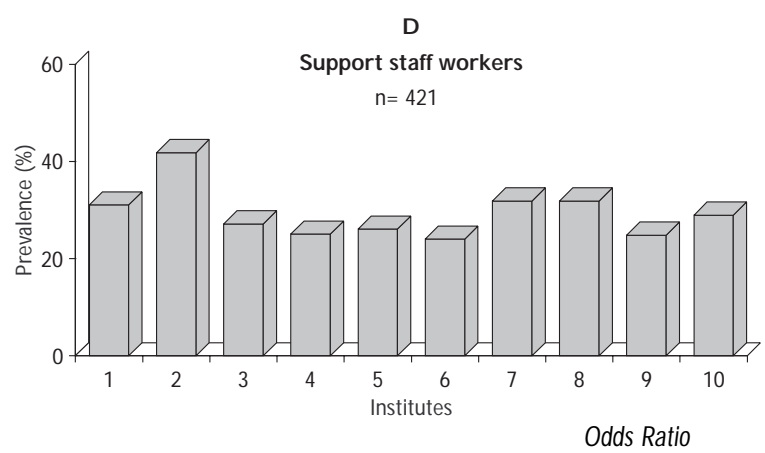

$\begin{array}{lll}\text { Psychiatry } & \text { vs } & \text { Oncology } \\ \text { Psychiatry } & \text { VS } & \text { Cardiology } \\ \text { Psychiatry } & \text { Vs } & \text { Respiratory-Diseases } \\ \text { Psychiatry } & \text { VS } & \text { N eurology } \\ \text { Psychiatry } & \text { VS } & \text { IN N SZ } \\ \text { Psychiatry } & \text { VS } & \text { Pediatrics } \\ \text { Psychiatry } & \text { VS } & \text { Perinatology } \\ \text { Psychiatry } & \text { VS } & \text { Children's Hospital } \\ \text { Psychiatry } & \text { VS } & \text { GHMGG }\end{array}$

(95\% Confidence Limits)

$0.66(0.22-1.75)$

$1.22(0.66-2.27)$

$1.36(0.71-2.62)$

$1.29(0.58-2.88)$

$1.45(0.76-2.75)$

$1.57(0.41-2.29)$

$0.96(0.50-1.80)$

$1.36(0.73-2.52)$

$2.56(1.29-5.09)$

The mean prevalence of smoking physicians was $22 \%$, for administrative staff $33 \%$, for researchers $25 \%$, and for support staff workers was $24 \%$. For identification of each Institute you can see the next list:

\begin{abstract}
$1=$ Psychiatry
$2=0$ ncology

$3=$ Cardiology

$4=$ Respiratory Diseases

$5=$ Neurology
\end{abstract}

$6=I N N S Z$

$7=$ Pediatrics

$8=$ Perinatology

$9=$ Children's Hospital

$10=$ GHMG
Instituto $\mathrm{N}$ acional de la N utrición Salvador Zubirán

Instituto Nacional de Pediatría

Instituto $\mathrm{N}$ acional de Perinatología

Hospital Infantil de México Federico Gómez Hospital General D r. Manuel Gea G onzález

\section{Figure 1. Comparison of SMOKING PREVALENCE BY INSTITUTES ACCORDING to EMPLOYMENT TYPE}




\section{Table IV \\ SMOKERS' SELF-DESCRIBED ATTITUDES AMONG WORKERS BY UNPLOYMENT TYPE, at the National Institutes of Health in Mexico City, 1997}

\begin{tabular}{|c|c|c|c|c|c|c|}
\hline \multirow[b]{2}{*}{ Smokers who want to quit } & \multirow{2}{*}{$\begin{array}{l}\text { Physicians } \\
69\end{array}$} & \multirow{2}{*}{$\begin{array}{c}\text { Administrative Staff } \\
173\end{array}$} & \multirow{2}{*}{$\begin{array}{c}\text { Researchers } \\
27\end{array}$} & \multicolumn{2}{|c|}{ Support Staff Workers } & \multirow{2}{*}{$\begin{array}{r}\text { Average } \\
32 \%\end{array}$} \\
\hline & & & & 161 & & \\
\hline & $(29 \%)$ & $(38 \%)$ & $(24 \%)$ & $(38 \%)$ & & \\
\hline \multirow[t]{2}{*}{ Smokers who do not want to quit } & 65 & 68 & 37 & 72 & & $23 \%$ \\
\hline & $(27 \%)$ & $(15 \%)$ & $(32 \%)$ & $(17 \%)$ & & \\
\hline \multirow[t]{2}{*}{ Smokers who have quit sometime in the past } & 104 & 210 & 51 & 188 & & $45 \%$ \\
\hline & $(44 \%)$ & $(47 \%)$ & $(44 \%)$ & $(45 \%)$ & & \\
\hline \multirow[t]{2}{*}{ Total } & 238 & 451 & 115 & 421 & & 1225 \\
\hline & $\begin{array}{c}\text { Odds Ratio } \\
\text { (95\% Confidence Limits }\end{array}$ & & & & \multicolumn{2}{|c|}{$\begin{array}{l}\text { Odds Ratio } \\
\text { (95\% Confidence Limits) }\end{array}$} \\
\hline Physicians vs. Administrative Staff & $0.42(0.26-0.66)$ & \multicolumn{3}{|c|}{ Administrative Staff vs. Researchers } & \multicolumn{2}{|c|}{$3.49(1.90-6.42)$} \\
\hline Physicians vs. Researchers & $1.45(0.76-2.77)$ & \multicolumn{3}{|c|}{ Administrative Staff vs. Support StaffW orkers } & \multicolumn{2}{|c|}{$1.15(0.76-1.73)$} \\
\hline Physicians vs. Support Staff W orkers & $0.48(0.30-0.76)$ & \multicolumn{3}{|c|}{ Researchers vs. Support StaffW orkers } & \multicolumn{2}{|c|}{$0.33(0.18-0.60)$} \\
\hline
\end{tabular}

observed in this work to that of the short version applied at the Institute of Respiratory Diseases (30\%), and the prevalence $(25 \%)$ of the 1993 National Survey ${ }^{3}$ provides external validity to our observations. One flawof these results is the different response rate observed among the Institutes. If the calculated prevalence of smoking were based on response rates at the different Institutes, one could expect it to be different if the Institutes with the lowest response rate were eliminated from the analysis. However, our results showed that the global prevalence of smoking remained very similar with or without the Institutes of Oncology and Neurology. The absence of a significant difference suggests that the influence of the response rate on the global prevalence was low.

The Institute of Psychiatry (IP) had the highest prevalence of smoking. However, this figure could have been biased by the lower prevalence of smoking observed in the Institutes with the lower respondent rates. In order to determine this effect, in a new analysis in which the Institutes of Oncology and Neurology were eliminated, the IP remained as the Institute with the highest prevalence. These arguments support the view that the response rate did not significantly bias the prevalence of smoking in the sample. Nevertheless, despite these arguments we will not assume in this report that our information represents the entire
NIHM, rather it is the result of a voluntary survey from 4422 workers of the NIHM.

A significantly higher smoking prevalence was found among females. An explanation may be that a higher rate of respondent were women $(57 \%$ which is equal to 2525 subjects). However, the analysis of the smoking prevalence among women (39\%) from a total number of 1225 smokers (see Table II) showed that 478 women out of 2525 (19\%) are smokers while, 269 out of $1897(14 \%)$ men are smokers. This data suggest that this higher prevalence may be due to a real and progressive increase of tobacco smoking among women working at the NIHM. This phenomenon may be showing what is going on among the general population and suggest that specific actions for tobacco control among women are needed in Mexico.

Considering that the highest prevalence of smoking was observed at the Institute of Psychiatry, odds ratios significantly higher than 1.0 indicate that workers of the IP were significantly more likely to be smokers than those who work at different Institutes. Our results based on this type of statistical analysis showed a clear association between smoking and the Institute of Psychiatry. The stepwise approach that we used may lead to some problems. ${ }^{6}$ Firstly, colinearity may be common. However, it was not present in any of the different regression models. The stepwise 
regression may yield models which are too small eliminating very significant variables. However, the different covariables that we entered in the regression remained significant in the final model with exception of the Institute of Oncology, as we previously anticipated. Another inconvenience is that the method may yield confidence intervals which are falsely narrow. This was not the case as can be observed in our results. In conclusion, despite the potential problems of the stepwise regression models, we consider that they did not affect our results.

The high prevalence of smokers among patients with psychiatric disorders, particularly among those with schizophrenia and bipolar affective disorder is a recognized phenomenon. ${ }^{7,8}$ In contrast, there is less information on the prevalence of smoking among the various employees of psychiatric units. In a national survey of 3327 hospitals in the United States of America (USA) to assess the compliance with policy for tobacco control, hospitals providing psychiatric and/or substance abuse services had lower than average rates of compliance. ${ }^{9}$ According to the authors these lower rates of compliance were due to smoking among patients and their visitors rather than the staff. In another study, Joseph and coworkers ${ }^{10}$ found that the number of psychiatric treatment beds was a factor associated negatively with the implementation of a smoke-free policy ( $\mathrm{OR}=\mathrm{O} .57,95 \% \mathrm{CI}=0.41-0.81)$. These reports are consistent with our results.

The highest rates of smoking were found among administrative staff and support staff. The $30 \%$ prevalence among the administrative staff workers from the Johns Hopkins Medical Institutions in 1990, before a program to ban smoking in medical areas is similar to the results of this study, suggesting a particular problem within this group of workers. ${ }^{11}$ The prevalence of smokers among physicians in the Johns Hopkins Medical Institutions before and after the program to ban smoking was $5.5 \%$ and $2.7 \%$, respectively. Similar figures were reported in a national survey in the USA between 1987 to $1990 .{ }^{12}$ A hospital in Cardiff, South Glamorgan ${ }^{13}$ reported similar numbers. All of these were much lower than that observed in this report $(22 \%)$ as well as lower than those reported by TapiaConyer and coworkers in a broader sample of Mexican physicians $(27 \%) .{ }^{5}$ These observations may have implications on the capacity as role model of physicians in the process of advocating against smoking. Of the physicians, those from the IP showed a higher significant prevalence of smokers $(54 \%)$ than the other Institutes.

The information on smoking habits among psychiatrists and psychologists is scarce. In a paper by
Smith and Grant ${ }^{14} 18 \%$ of the medical staff, including pychiatrists and psychologist indicated that they smoked. Although the data came from different settings, the medical staff of the psychiatric unit from the Smith and Grant study seem to have a higher prevalence than physicians in general. ${ }^{11-13}$ This information is consistent with the national survey in the USA published by Nelson and colleagues ${ }^{12}$ showing that, whereas physicians exhibited a $5.5 \%$ prevalence of smoking, psychologist showed a much higher prevalence, $17 \%$ which is, proportionally speaking, similar to that found in this paper although our figures are much higher. There is no single clear explanation for this result. One could speculate that these specialists smoke more often than other medical specialists, because of the high prevalence of smoking among their patients, so they start to smoke as a strategy to bond with their patients.

The prevalence of smokers within the Institutions seems to be high in Mexico. One explanation may be the lack of strict institutional policies to limit smoking to certain areas. Forty six percent of the smokers indicated that they smoke at work. The administrative staff and researchers reported a higher significant number of subjects who smoke in their areas of work, while that for the support staff workers and physicians was lower. One explanation might be the privacy that the administrators and researchers have to smoke in their offices. In contrast, the nurses and the support staff workers who do not have a specific and private place to work in, smoke less. Interestingly, these workers more frequently expressed the desire to quit smoking. If we consider the number of smokers who have quit some time in the past as subjects who want to quit currently, $78 \%$ of the current smokers need help to quit smoking. Therefore, the results of this work suggest that more restrictions are needed to ban smoking in medical facilities.

\section{Limitations}

For this survey we issued personal invitations to answer the questionnaire which lead to spontaneous acceptance to do it. In order to avoid any kind type of distrust, the identification of the workers was option$\mathrm{al}$, and since the questionnaire was self-administered, there was no way to identify them. Nevertheless, the most surprising finding of this report was the low response rate $(31 \%)$. There are probably several explanations for this. One of these might be the cultural pattern that surrounds smoking. Another may be the methods used to gather the information from the questionnaires. Perhaps a more persuasive method to con- 
vince employees to answer this type of surveys should be used for future studies. But whatever the cause, this low response rate is the most important limitation of this work. Despite this limitation, the similar prevalence observed from the short version of the questionnaire with a more comprehensive rate of respondents suggests that the low response rate was not a decisive factor for the prevalence reported in this work. Furthermore the analysis per se of 4422 questionnaires from the workers of the NIHM may be important.

In summary, our results suggest that the prevalence of smoking in a sample of respondents from the National Institutes of Health in Mexico is very high. This prevalence is particularly high among the physicians compared to physicians from other medical Institutions in other countries. Apparently, the prevalence among the physicians from the Institute of Psychiatry is even higher. This proportion is similar to that from at least one national study in the USA suggesting that further research is needed on this topic. An important number of staff working at the NIHM smoke in their work areas. This may be due to tacit consent, lending credit to the suggestion that at least the following public health policies should be implemented atthe NIHM: 1) reinforcement of the existing legislation on tobacco control in hospitals and health institutions in Mexico; and 2) providing effective health promotion and health education programs in order to achieve: a) a progressive elimination of tobacco users in the medical institutions and b) effective protection from involuntary exposure to tobacco smoke. Furthermore, because an important number of subjects indicated that they want to quit smoking, an effective program for smoking cessation as well as for research on smoking control strategies are needed in the NIHM.

\section{A cknowledgment}

The writers wish to thank to Dr. Johnatan Samet and Dr. Caleb Alexander for their comments on the manuscript, and Ruth Hernández for her secretarial assistance.

\section{References}

1.US D epartment of $\mathrm{H}$ ealth and $\mathrm{H}$ uman Services. The health consequences of smoking: cancer. A report of the Surgeon General, 1982. Rockville, Maryland: Public Health Service 0 ffice on Smoking and Health, 1982. [DHHS Publication N 0. (PHS) 82-50179].

2. Hanrahan J, Sherman C, Bresnitz E, Emmons K, Mannino D. Cigarette smoking and health. American Thoracic Society. Am J Respir Crit Care Med 1996;153:861-865.

3. Secretaría de Salud, Dirección General de Epidemiología, Instituto Mexicano de Psiquiatría. Encuesta $\mathrm{N}$ acional de Adicciones, Tabaco. México D.F.: SSA, 1993.

4. Tapia-C onyer R, Kuri MP, Meneses GF. Smoking-attributable mortalityMexico 1992. MMW R - Morb Mortalil W kly Rep 1995;44(19):372-381.

5.Tapia-C onyer R, Cravioto P, D e la Rosa B, Galván F, García-de laTorre G, Kuri P.C igarette smoking; knowledge and attitudes among Mexican physicians. Salud Publica Mex 1997;39:507-512.

6. Derksen S,Andersen PK. Backward, forward and stepwise automated subset selction algorithms: Frecwuency of obtaining authentic and noise variables. Br Math Stat Psycol 1992;45:265-282.

7. Covey LS, Hughes DC, G lassman AH, Blazer DG, George LK. Eversmoking, quitting, and psychiatric disorders: Evidence from the Durham, North Carolina, Epidemiologic Catchment A rea. Tobacco Control 1994;3:222-227.

8. Hughes JR, H atsukami DK, Mitchel JE, D ahlgren BA. Prevalence of smoking among psychiatric outpatients. Am J Psychiatry 1986;143:993-997.

9. Longo DR, Brownson RC, Kruse RL. Smoking bans in US hospitals. Results from a national survey. JAMA 1995; 274(6):488-490.

10. Joseph AM, Knapp JM, N ichol KL, Pirie PL. Determinants of compliance with a national smoke-free hospital standard. JA MA 1995;274(6):491-494. 11. Stillman FA, Becker D M, Swank RT, Hantula D, Moses H, G lantz S et al. Ending smoking at the Johns Hopkins Medical Institutions. An evaluation of smoking prevalence and indoor air pollution. JAMA 1990; 264:1565-1569.

12. N elson DE, Emont SL, Brackbill RM, Cameron LL, Peddicord J, Fiore MC. Cigarette smoking prevalence by occupation in the United States. A comparison between 1978 to 1980 and 1987 to 1990. J 0 ccup Med 1994; 36:516-525.

13. Hussain SF,Tjeder-Burton S, C ampbell I, D avies PO .Attitudes to smoking and smoking habits among hospital staff.Thorax 1993; 48:174-175. 14. Smith W, G rant B. Effects of a smoking ban on general hospital psychiatric service. Hosp Community Psychiatry 1989; 40(5):497-502. 